\title{
Introducing the Time and the Arts Special Edition: a Note from the Editor
}

\author{
Rose Harris-Birtill \\ $\mathrm{UK}$
}

I write this introduction to the Time and the Arts special issue of KronoScope: Journal for the Study of Time having recently returned from the International Society for the Study of Time's 17th Triennial Conference, held at Loyola Marymount University in California, U.S., in June 2019. The conference theme, 'Time in Variance', was a vibrant celebration of the vital diversity of perspectives within the field. In addition to papers from the disciplines of physics, maths, computer science, history and law, there were papers on time from across the arts, including presentations on literature, film, art installations, animation, music, performance, television and video games. It seems particularly fitting, then, that this first edition of KronoScope following the conference is a special issue dedicated to the unique contributions of the arts to the study of time. Variously confronting the topics of quantum physics, trauma, grief, climate change and the Anthropocene from literary, philosophical, photographic and theatrical perspectives, the articles in this issue demonstrate the originality of time research taking place across the imaginative disciplines and the essential contribution of the arts to our shared understandings of time.

Opening the special edition, Victoria Carpenter and Paul Halpern's article, 'A Bridge between Worlds: Time and the Observer in "The Celestial Plot" by Adolfo Bioy Casares', contributes a truly interdisciplinary perspective to its analysis of this Latin American writer's science fiction, combining artistic, scientific and philosophical approaches. Drawing on literary criticism and quantum physics, Carpenter and Halpern present a detailed close reading of Casares's short story, in which its protagonist traverses multiple realities while test flying a plane. Analysing its key characters and objects, this article argues that Casares's story, published in 1948, remarkably anticipates the 'Many Worlds' notion advanced in the late 195 os by physicist Hugh Everett. Everett's theorywhich states that reality bifurcates during quantum measurements, leading to near-identical copies of observers — is presented alongside Carpenter's and 
Halpern's sophisticated reading of the multiple universes depicted in the story, demonstrating that science fiction can pre-empt scientific advancement.

Continuing this discussion of science and literature, '(Post)human Temporalities: Science Fiction in the Anthropocene' by Jonathan Hay analyses the shifting portrayal of climate change across four science fiction works from the last three decades. Analysing Kim Stanley Robinson's Mars Trilogy, Jeanette Winterson's The Stone Gods, Michel Faber's The Book of Strange New Things, and Paolo Bacigalupi's The Water Knife, Hay examines their shared presentation of a painful reality by which the long-term survival of our species is by no means certain. Hay's perceptive close readings of the posthuman perspectives underpinning each text demonstrate the urgency of change in an increasingly precarious future, arguing that this cross-section of representative fictions is indicative of a rapidly fluctuating Western outlook on climate crises.

Confronting climate change from the perspective of visual rather than textual narratives, 'Re-Viewing Western U.S. Rephotography in the Anthropocene' by William Handley examines an artistic practice whereby nineteenth-century survey photographs of western U.S. landscapes have been 're-photographed' in the present, with the same sites revisited and recaptured a century later, revealing the historical and geological changes that have taken place during this time. Through these haunting images, Handley argues that these photographs expose a relationship between temporal continuity and change that is deeply linked with the history of American exceptionalism and expansion. Deftly analysing the phenomenon of rephotography in light of ongoing debates on the Anthropocene, Handley argues that rephotography presents a new method of seeing that sharpens and slows our visualisation of time-an invaluable approach in light of the lack of human foresight that has contributed to the current climate crisis.

Investigating the narration of personal trauma across both visual and textual storytelling, 'Connie Palmen's and Jan Fabre's Grief staged as Landscape of Memory' by Sylvia Solakidi examines the shared temporal strategies used to confront and work through personal grief in Palmen's writing and Fabre's theatre. Comparing Palmen's intimate notes on her experience of bereavement in The Logbook of a Merciless Year and Fabre's haunting performance piece Requiem for a Metamorphosis, a work created following the death of his parents, this article explores each work's unflinching confrontation of grief and its painful effects on the body. Discussing the corporeality of grief, Solakidi examines the ways that each author enacts their memories of loved ones in the present in order to move towards future healing after seemingly insurmountable loss. 
Similarly confronting devastating but unspeakable personal trauma, 'Present-tense narration and representing trauma in Anne Enright's The Gathering' by Karen Anne McCarthy investigates the use of present-tense narration in Enright's Booker Prize-winning novel in order to understand the literary relationships between trauma and time. As McCarthy demonstrates, this narrative temporal strategy is used to confront its narrator's witnessing of an unnamed traumatic 'event' which resists conventional linear narration, using a form of 'exploded timeline' to convey its far-reaching effects. Through a deft close reading, McCarthy argues that its narrator's inability to occupy the narrative present in the wake of family crises is indicative of a broader literary technique that employs simultaneous narrative temporalities, and whose temporal strategies are finally used to suggest the possibility of healing within a future yet-to-come.

Together, these papers are a testament to the breadth, depth and originality of time scholarship in the arts, demonstrating the essential variety of today's perspectives in the field. With their diversity of approaches, these articles together form a powerful collection of individual and collective perspectives that reinforce the value of the human imagination in the study of time. Research into representations of time in the arts provides us with a vital means of venturing into imaginative spaces, revisiting our pasts and reimagining our futures through another's eyes. That such scholarship persists amidst a worrying trend of diminishing funding for arts and humanities research is vital amidst our current ecological and humanitarian crises. We must protect these vital imaginative spaces; without them, we forget how to dream. As these papers show, if we are to find the agency to create alternative ethical futures for ourselves-whether finding the courage to continue in the face of unspeakable personal traumas, or the global crises heralded by the Anthropocene-we must first be able to imagine them. 